\title{
Osseous Dysplasia Secondary Infection: A Case Report
}

\author{
Paul Niang, Abdou Ba, Babacar Tamba, Alpha Kounta, Mamadou Diatta \\ Oral Surgery Department, Cheikh Anta Diop University, Dakar, Senegal \\ Email: dbniang@hotmail.com
}

How to cite this paper: Niang, P., Ba, A., Tamba, B., Kounta, A. and Diatta, M. (2018) Osseous Dysplasia Secondary Infection: A Case Report. Surgical Science, 9, 109-114.

https://doi.org/10.4236/ss.2018.93011

Received: November 3, 2017

Accepted: March 18, 2018

Published: March 21, 2018

Copyright (C) 2018 by authors and Scientific Research Publishing Inc. This work is licensed under the Creative Commons Attribution International License (CC BY 4.0).

http://creativecommons.org/licenses/by/4.0/

(c) (i) Open Access

\begin{abstract}
Introduction: Osseous dysplasia is a benign tumor of the jaws predominantly occurring in melanoderm women. The pathogenesis remains unknown. Its often fortuitous discovery usually is in the fourth decade of life. Its treatment involves surgery. Our aim was to report a case of osseous dysplasia secondary infection in Senegal. Observation: The over sixty-year-old patient initially came for recurring old suppuration. A prior history of dental avulsions and self-medication was found out. The clinical features were predominant chronic osteitic manifestations. Its radiologic presentation suggested a florid form. The combination of spiramycin-metronidazole had to be given twice. The isolated sequestrum was enucleated and the anatomopathology confirmed the diagnostics. Discussion: The patient's age conformed to late discovery due to silent progression and poor access to medical care. The prior iatrogenic avulsions can be explained by the absence of systematic radiological exploration and by the unawareness of the inconspicuous tumor. The clinical and radiological features at this stage of the osseous dysplasia secondary infection were typical. The treatment and the follow-up were dependent on the prevailing work conditions. Conclusion: The chronic osteitic manifestations are indicative of osseous dysplasia in elderly women in Senegal.
\end{abstract}

\section{Keywords}

Osseous Dysplasia, Jaws, Secondary Infection, Senegal

\section{Introduction}

According to the WHO, osseous dysplasia or cementoma is a benign odontogenic tumor of the jaws, with a predilection for melanoderm women [1] [2] [3] [4] [5]. The pathogenesis remains unknown [6] [7] [8]. Its discovery is often fortuitous in the fourth decade of life [3] [4] [5] [9]. The florid form is at least 
bilateral mandibular and poorly expansive [1] [2] [5] [10]. But the secondary chronic osteitic manifestations were identified in $11 \%$ to $76.7 \%$ of cases in a context similar to ours [1] [2] [11]. Deformation, mucosal or cutaneous fistula and oral exposure are predominant clinical symptoms at this stage of progression [1] [2] [6]. Its presumption is based particularly on radiology and is confirmed by anatomopathology [1] [2] [3]. Surgery is indicated in case of secondary infection and/or substantial deformation [1] [2] [3] [9] [12] [13] [14]. Up to then, the recording of series was rare. Our aim was to report diagnostics and treatment of a case of osseous dysplasia secondary infection in Senegal.

\section{Observation}

The sixty year old patient lived in a rural area and came for an examination. A cutaneous suppuration preceded by the recurrent subacute painful episodes, over several years, treated by amoxicillin periodic self-medication led to the request for the exam. Prior dental avulsions and precarious therapy were noticed. Otherwise, the overall state of the patient was preserved.

Through extra-oral inspection, a discrete deformation and a lower right homolateral cutaneous chin fistula were noticed (Figure 1). Upon palpation, the deformation was painless, hard and integral with the bone. The fistula was oozing out. Labiomental sensitivity was preserved. The basilar edge was regular. There was no adenopathy.

Through oral inspection, yellowish homolateral gaping dental avulsion sites, a normal mucosa and the deformation of the two bone entities were noticed. Upon contact, the residual alveoli were painless.

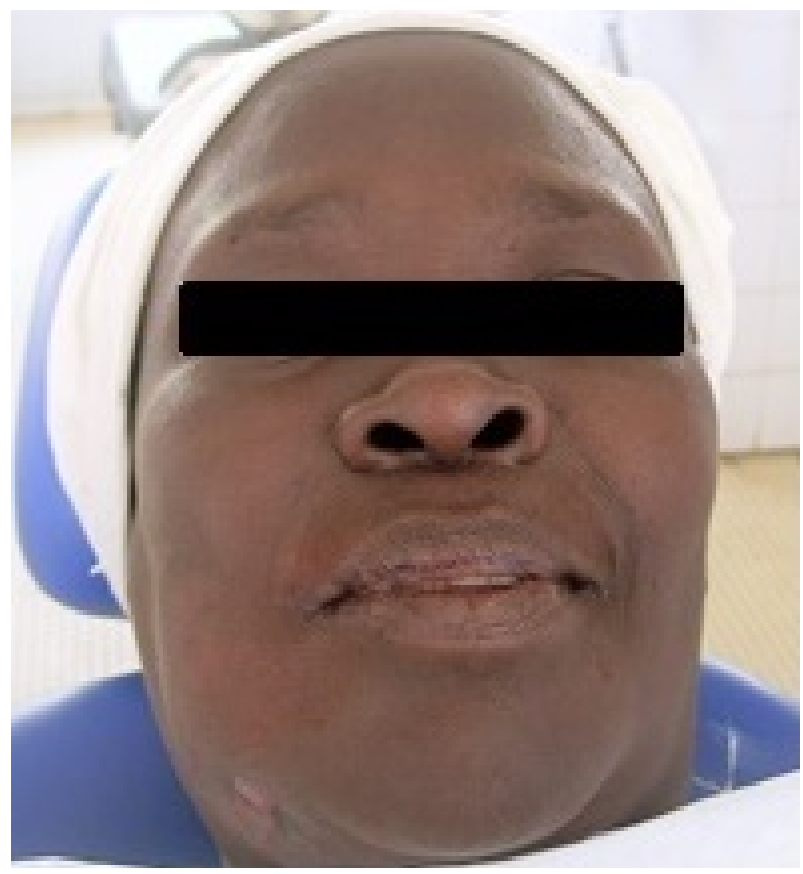

Figure 1. Right lower chin deformation and homolateral submandibular fistula. 
The orthopantomogram (OPT) showed opaque polylobular, heterogenous, bilateral masses like ginger roots, encompassing the roots, surrounded with a clear border extending beyond the mandibular canal defining a right isolated sequestrum (Figure 2). The adjacent dental roots were elongated or deformed into a "drumstick".

An antibiotic cure combining spiramycin and metronidazole at 6 million IU and of $1 \mathrm{~g}$ per day, in two doses, over ten days was prescribed. It was renewed for the same reason when the patient came back after a three month absence. The residual alveoli were then loose. The isolated sequestrum was picked up through the gaping avulsion site under mandibular foramina locoregional anesthesia (Figure 3 and Figure 4). A mouth mirror was used as cheek and lip retractor.

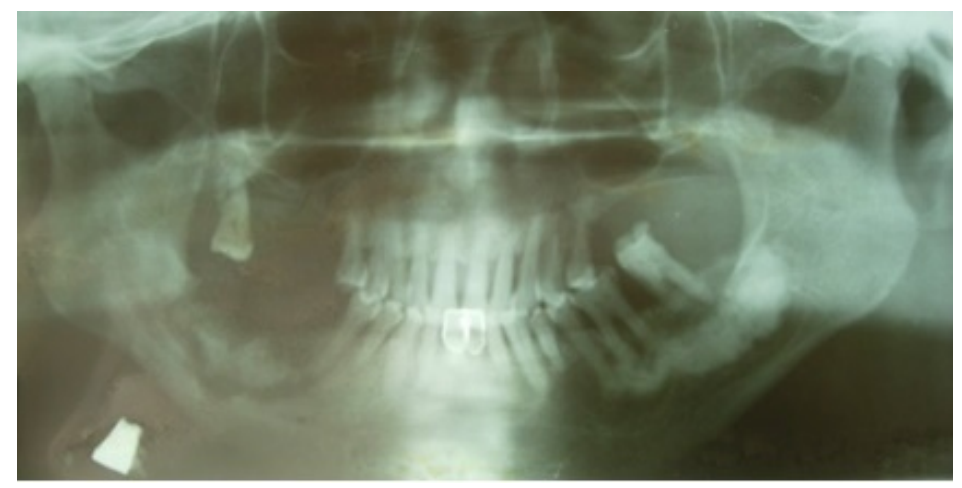

Figure 2. Bilateral mandibular sequestrations.

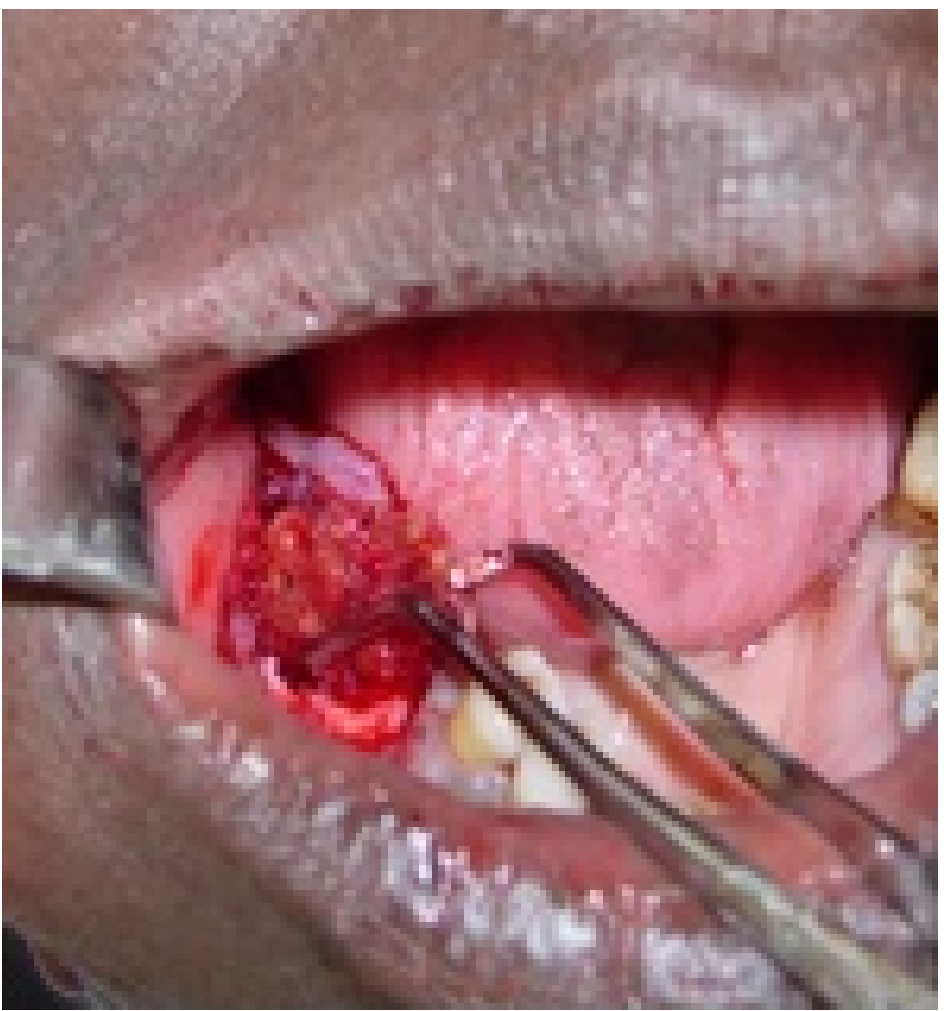

Figure 3. Picked up isolated sequestrum. 


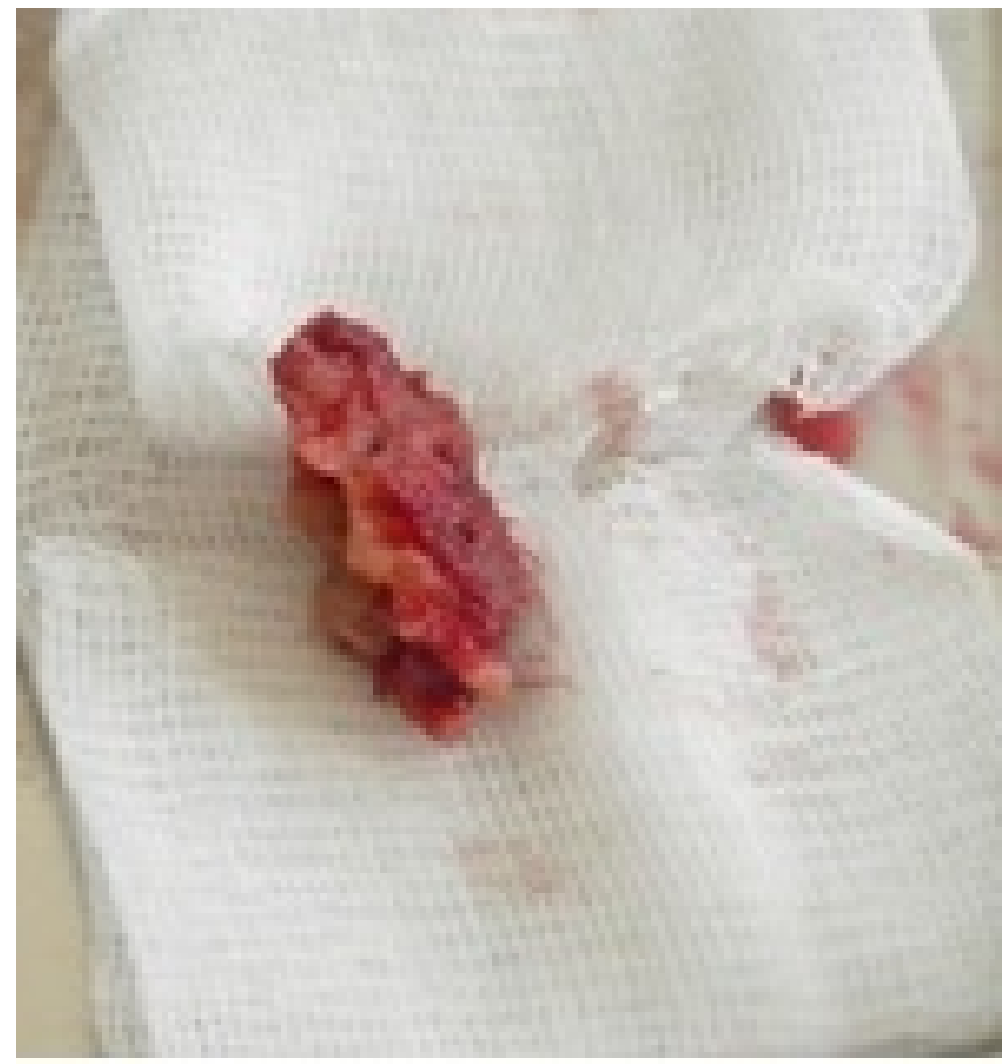

Figure 4. Enucleated surgical specimen.

Oral mucosal exposure edges were raised with a periosteal elevator. The sequestrum was moved with a straight dental root elevator then picked up with curved tweezers. The residual cavity was carefully scratched with a sharp spoon, in order not to damage the lower alveolar nerve then cleansed with physiological serum. Non resorbable sutures were made with needle holder and operating scissors.

An extemporaneous anatomopathological examination confirmed the preliminary diagnostics. After sutures removal, there was no further contact with the patient and no follow-up was possible.

\section{Discussion}

In this case report, the epidemiological profile, symptoms route and the treatment strategy can summarize features of osseous dysplasia in West Africa.

Female predilection is commonly reported [1] [2] [6] [7] [8].

The clinical features reflect osseous dysplasia descriptions at that stage of progression. Presumption was based on epidemiological, clinical and radiological features. The combination of slow progression, chronic osteitic manifestations and oral exposure reflects osseous dysplasia at that stage of progression [1] [2] [6] [11]. The absence of family history, the slow progression and the bilateral location are suggestive of the florid form.

The silent progression, the poor access to medical care and the self-medication 
explain why it showed up later than at the usual fourth decade of life [1]. Dental avulsions corroborate the lack of systematic radiological exploration that has already been reported to be common in Senegal [1] [5]. Precarious therapy history reflects the unawareness of the underlying tumor. The oral exposure induced by the iatrogenic dental avulsions explains the secondary osteitic manifestations that were chronic from the onset and sustained by the avascular tumerous tissue [1] [2].

$\mathrm{X}$-ray presentation was indicative of maturing florid osseous dysplasia [1] [5] [8] [13]. The elongated or deformed into a "drumstick" adjacent dental roots were indicative of dental origin tumor [1]. Although internal osseous entity was deformed, preserved labiomental sensitivity despite of lower alveolar nerve involvement was indicative of benign process.

The combination of spiramycin-metronidazole took into account the osseous site, the anaerobic predominance and the oral exposure. Indeed, the elimination of spiramycin is salivary. The dosing took into account the age. Antibiotic treatments have enabled a "delay" up to the cleavage showing up in the mouth with a loose alveoli and the continuity of the border on the X-ray.

Maturation and cleavage favor the integral sequestrum enucleation [1]. Moreover a reduced and elementary surgical instruments set was used. The sutures made it possible to avoid food accumulation in the residual cavity. The non resorbable silk compelled the patient to keep in touch with us, until its removal.

Abstention is recommended for silent locations [1] [2] [3] [9] [12] [13]. Surgical trauma would entail the risk of tumoral process acceleration [2] [3] [9] [12] [13]. Like dental avulsions, biopsy would entail the risk of secondary infection [13].

Interruption of follow-up is due to poor access to medical care.

\section{Conclusions}

This case report illustrates the impact of the prevailing work conditions and background on the development, on the diagnosis and therapy of a benign tumor of the jaws. Beyond the underlying osseous dysplasia, a dental avulsion is carried out without prior radiography, with the risk of being iatrogenic. Chronic osteitic manifestations are indicative of osseous dysplasia in an elderly woman in Senegal, and in that situation:

- Search for an exposure route to the oral septicity;

- Systematically request an OPT;

- Provide for an antibiotic cure until the imminent sequestration of secondarily infected sites;

- Avail yourself of the exposure route and the cleavage for complete enucleation and reduction of the surgical follow-up.

\section{References}

[1] Niang, P., Dia-Tine, S., Tamba, B., Diatta, M., Ba, A., Kounta, A., Gassama-Barry, 
C.B. and Diallo, B. (2013) Aspects épidémiologiques, cliniques, radiographiques et thérapeutiques des cémentomes. Expérience d'un service de chirurgie buccale. ReV Col Odonto-Stomatol Afr Chir Maxillo-Fac, 20, 10-15.

[2] Alsufyani, N.A. and Lam, E.W. (2011) Osseous (Cemento-Osseous) Dysplasia of the Jaws: Clinical and Radiographic Analysis. Journal (Canadian Dental Association), 77, b70.

[3] Ogunsalu, C.O. and Miles, D. (2005) Cemento-Osseous Dysplasia in Jamaica: Review of Six Cases. West Indian Medical Journal, 54, 264-267. https://doi.org/10.1590/S0043-31442005000400012

[4] Cho, B.H., Jung, Y.H. and Nah, K.S. (2007) The Prevalence, Clinical and Radiographic Characteristics of Cemento-Osseous Dysplasia in Korea. Korean Journal of Oral and Maxillofacial Radiology, 37, 185-189.

[5] Larroque, G., Cantaloube, D., Ndiaye, R. and Sans, H. (1990) Radiological Aspects of Giant Cementoma of the Jaws (Pindborg). Actual Odontostomatol, 44, 95-101.

[6] Benazzou, S., Boulaadas, M., El Ayoubi, A., Nazih, N., Essakalli, L. and Kzadri, M. (2011) Florid Cemento-Osseous Dysplasia of the Jaws. Revue de Stomatologie et de Chirurgie Maxillo-Faciale, 112, 174-176. https://doi.org/10.1016/j.stomax.2011.01.004

[7] Martini, M.Z., de Carvalho Júnior, J.P. and Soares, H.A. (2006) Surgical Management of an Infected Aggressive Florid Cemento-Osseous Dysplasia. Report of a Case. Minerva Stomatologica, 55, 515-521.

[8] Gonçalves, M., Píspico, R., Alves, F.A., Lugão, C.E. and Gonçalves, A. (2005) Clinical, Radiographic, Biochemical and Histological Findings of Florid Cemento-Osseous Dysplasia and Report of a Case. Brazilian Dental Journal, 16, 247-250.

[9] MacDonald-Jankowski, D.S. (2008) Focal Cemento-Osseous Dysplasia: A Systematic Review. Dentomaxillofacial Radiology, 37, 350-360.

https://doi.org/10.1259/dmfr/31641295

[10] Barnes, L., Eveson, J.W., Reichart, P. and Sidransky, D. (2005) Pathology and Genetics of Head and Neck Tumours. World Health Organization Classification of Tumours. IARC Press, Lyon.

[11] Kawai, T., Hiranuma, H., Kishino, M., Jikko, A. and Sakuda, M. (1999) Cemento-Osseous Dysplasia of the Jaws in 54 Japanese Patients: A Radiographic Study. Oral Surgery, Oral Medicine, Oral Pathology, Oral Radiology, and Endodontology, 87, 107-114. https://doi.org/10.1016/S1079-2104(99)70303-3

[12] Goncalves, M., Pispico, R., Alves Fde, A., Lugao, C.E. and Goncalves, A. (2005) Clinical, Radiographic, Biochemical and Histological Findings of Florid Cemento-Osseous Dysplasia and Report of a Case. Brazilian Dental Journal, 16, 247-250. https://doi.org/10.1590/S0103-64402005000300014

[13] Noffke, C.E.E., Ngwenya, S.P., Nzima, N., Raubenheimer, E.J. and Rakgwale, N.B. (2012) Gigantiform Cementoma in a Child. Dentomaxillofacial Radiology, 41, 264-266. https://doi.org/10.1259/dmfr/13435626

[14] Salem, Y.M., Osman, Y.I. and Norval, E.J. (2010) Focal Cemento-Osseous Dysplasia: Review and a Case Report. $S A D J, 65,422-423$. 